\title{
Spinal anaesthesia for single level spine surgery: comparison between bupivacaine with fentanyl and bupivacaine with clonidine
}

\author{
Madhava Reddy $\boldsymbol{R}^{1^{*}}$, Nandini D Prasad ${ }^{2}$, Rashmi S Shankar ${ }^{2}$ \\ Professorl $^{1}$, Resident ${ }^{2}$ Department of Anaesthesiology, \\ Kempegowda Institute of Medical Sciences, Bangalore, Karnataka, India.
}

\begin{abstract}
Background:
Spinal anaesthesia is safe and effective for lumbar spine surgeries. Adequate analgesia and patient's comfort are to be taken care of in prone position. So, we compared fentanyl and clonidine added to bupivacaine in patients undergoing single level spine surgery under spinal anaesthesia.
\end{abstract}

\begin{abstract}
Materials and methods:
Sixty patients aged 18 and 50 years of either sex were randomly allocated into two groups. Group F received $50 \mu \mathrm{g}$ of fentanyl and group $\mathrm{C}$ received $50 \mu \mathrm{g}$ of clonidine as adjuvants to $3 \mathrm{ml}$ of $0.5 \%$ bupivacaine. Duration of analgesia, sedation and patient's comfort were assessed.
\end{abstract}

\section{Results:}

Duration of analgesia was $193.5 \pm 15.6$ and $440.7 \pm 31.9$ minutes in group $\mathrm{F}$ and group $\mathrm{C}$ respectively. All patients in group $\mathrm{C}$ were comfortable in prone position. 4 patients in fentanyl group received propofol infusion.

\section{Conclusion:}

Intrathecal fentanyl and clonidine are safe and effective adjuvants to bupivacaine in prone position whereas clonidine is better in providing intraoperative patient's comfort and postoperative analgesia.

Keywords: Spinal anaesthesia; spine surgery; intrathecal fentanyl; intrathecal clonidine; hyperbaric bupivacaine

\section{Introduction}

Lumbar spine surgeries are performed via a posterior approach while the patients are usually in prone position. Duration of surgery depends on the underlying pathology, clear operative field and surgeon's performance. Most of these spine surgeries are associated with a painful postoperative period, hence well planned postoperative analgesia is the main concern for the anaesthesiologist. ${ }^{1,2}$
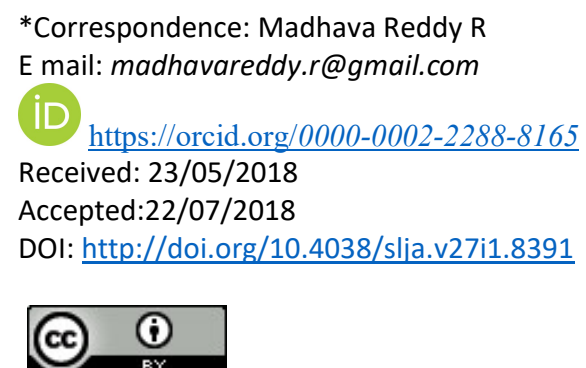

The advantages of lumbar spine surgeries under regional anaesthesia over general anaesthesia has been proven by many authors with respect to avoiding polypharmacy, reduction in intraoperative blood loss, reduction in the surgical procedure time, better maintenance of intraoperative haemodynamics, better communication with the patient, postoperative analgesia, cost effectiveness etc. ${ }^{2,3,4,5}$ Inspite of knowing these advantages, spinal anaesthesia for spine surgery is not well accepted by many anaesthesiologists, reasons being duration of analgesia is limited when local anaesthetics are used alone. In an event of prolongation of surgical time it will be a difficult task for the anaesthesiologist to convert to general anaesthesia in prone position, patient will be anxious and uncomfortable on the spine frame inspite of receiving regular sedation. In turn the surgeon will be apprehensive to operate on a restless patient. To avoid these problems many authors in previous studies have supplemented their patients with intravenous propofol infusion which 
is as good as administering two anaesthetic techniques simultaneously.

Avoiding multiple techniques, yet to achieve desired duration of analgesia, sedation and comfort of the patient in prone position, addition of intrathecal adjuvants with good sedative properties is a better alternative. Such adjuvants not only prolong the duration of block but also the resultant sedation helps in alleviating patient anxiety intraoperatively, thereby helping in achieving better acceptance of regional anaesthesia for spine surgery by surgeons and anaesthetists. Intrathecal opioid and non-opioid adjuvants have been successfully used in many surgeries to prolong the duration of analgesia, whereas literature is lacking in use of such adjuvants intrathecally for spine surgeries to evaluate safety, efficacy and patient comfort in prone position. Hence in this study our aim was to know the safety and efficacy of intrathecal fentanyl and clonidine as adjuvants to hyperbaric bupivacaine with respect to duration of block and patient's comfort in prone position for single level lumbar spine surgeries.

\section{Materials and methods}

After obtaining approval from the institutional ethics committee, written informed consent was taken from 60 patients between the age group of 18 50years of ASA 1 and 2 of either sex undergoing single level lumbar spine surgeries. Patients with history of previous spine surgeries, any contraindications to subarachnoid block, weighing more than $80 \mathrm{kgs}$, pregnancy and lactation were excluded for the study. Sample size was estimated by using the difference in mean duration of block between fentanyl and clonidine in previous studies and using these values at $95 \%$ confidence interval and $80 \%$ power. 29 patients were required per group, so we enrolled 30 patients in each group. Patients were randomly allocated into the two groups by a computer generated opaque closed envelope technique prepared by anaesthesiologist who was not part of the study. The envelopes were opened by the resident and the study drugs were prepared according to the group allocation. Group $\mathrm{F}$ received $3 \mathrm{ml}$ of $0.5 \%$ hyperbaric bupivacaine with $50 \mu \mathrm{gs}$ of fentanyl and group $\mathrm{C}$ received $3 \mathrm{ml}$ of $0.5 \%$ hyperbaric bupivacaine with $50 \mu \mathrm{gs}$ of clonidine amounting to a volume of $4 \mathrm{ml}$.

Basal vital parameters were recorded. No patients were given sedative premedication. Under aseptic precautions, with patients in sitting position, using a 26g Quincke needle at L3-4 or L4-5 interspace study drug was deposited intrathecally. Twenty minutes after putting back the patient to supine position and after achieving a desired sensory level of T8-T6 patients were placed in prone position.

Onset of sensory block, time to reach highest sensory level, onset and duration of motor block, time for two segment regression, duration of analgesia and level of sedation were noted. Sensory block was assessed by pin prick method, motor block by modified Bromage scale and sedation by Ramsay sedation score. Duration of analgesia is defined as time from the onset of sensory block till the patient complains of pain.

Intraoperatively vital parameters were recorded. Bradycardia (less than $60 \mathrm{bpm}$ ) and hypotension (fall in BP more than $20 \%$ of basal) were treated with $0.6 \mathrm{mg}$ of atropine and $6 \mathrm{mg}$ of ephedrine respectively. Patient's comfort in prone position was assessed by observing and questioning the patient. If the patients were anxious, restless or inadequately sedated and difficulty in maintaining the prone position were considered as uncomfortable they were supplemented with propofol infusion. Intraoperatively if the duration of analgesia was inadequate due to prolonged surgery, we planned to administer a second dose of spinal with $2 \mathrm{ml}$ of bupivacaine by the surgeon. Post operatively diclofenac $75 \mathrm{mg}$ was given intravenously as rescue analgesia when the patient complained of pain. Complications if any were noted and treated accordingly. Patients with inadequate level of block, failed block requiring second dose of spinal were excluded from the study.

Interpretation of data was carried out and analysed using SPSS 22 version of software. Categorical data was represented in the form of frequency and proportion. Chi Square test was used as test of significance for qualitative data. Continuous data was represented as mean and standard deviation. Independent $t$ test was used to identify the mean difference between two groups. P value $<0.05$ was considered statistically significant. 


\section{Results}

Among the 60 patients studied none were excluded from the study. The distribution of age, gender, anthropometric measurements and ASA status between the study groups were statistically not significant. (Table 1)

Table 1: Demographic data of the patients. (Chi square test)

\begin{tabular}{|l|l|l|l|}
\hline Characteristics & $\begin{array}{l}\text { Group F } \\
\mathrm{n}=30\end{array}$ & $\begin{array}{c}\text { Group C } \\
\mathrm{n}=30\end{array}$ & P value \\
\hline Age (in years) & $42.7 \pm 11.4$ & $41.4 \pm 8.4$ & 0.027 \\
\hline Gender (m:f) & $21: 9$ & $20: 10$ & 0.781 \\
\hline Height (cms) & $160.2 \pm 6.9$ & $161.1 \pm 5.2$ & 0.585 \\
& & & \\
& & & \\
\hline Weight (Kgs) & $62.8 \pm 5.7$ & $63 \pm 4.7$ & 0.922 \\
\hline ASA(1 and 2) & $25: 5$ & $26: 4$ & 0.718 \\
\hline
\end{tabular}

Onset of sensory block, onset of motor block, time to reach highest sensory level and duration of surgery were comparable between group $\mathrm{F}$ and group C. The mean time for two segment regression was $100 \pm 7.5$ minutes in group F and $269.4 \pm 28.9$ minutes in group $\mathrm{C}$ and its difference was statistically significant $(\mathrm{p}<0.001)$. Duration of motor block was $159.4 \pm 12.6$ minutes and $357.8 \pm 26.9$ minutes in group $\mathrm{F}$ and group $\mathrm{C}$ respectively with a significant difference between the two groups $(p<0.001)$. Statistically significant difference was observed between the two groups in respect to duration of analgesia, the values being $193.5 \pm 15.6$ minutes and $440.7 \pm 31.9$ minutes in group $\mathrm{F}$ and group $\mathrm{C}$ respectively $(\mathrm{p}<0.001)$. (Table 2)
Table 2: Characteristics of sensory block, motor block and duration of analgesia (Independent $t$ test)

\begin{tabular}{|l|c|l|l|}
\hline $\begin{array}{l}\text { Variables } \\
\text { (minutes) }\end{array}$ & $\begin{array}{l}\text { Group F } \\
\mathrm{n}=30\end{array}$ & $\begin{array}{l}\text { Group C } \\
\mathrm{n}=30\end{array}$ & $\mathrm{p}$ value \\
\hline $\begin{array}{l}\text { Duration of } \\
\text { surgery }\end{array}$ & $108.9 \pm 13$ & $113.5 \pm 13.6$ & 0.180 \\
\hline $\begin{array}{l}\text { Time of onset of } \\
\text { sensory block }\end{array}$ & $2.6 \pm 0.9$ & $2.7 \pm 0.8$ & 0.560 \\
\hline $\begin{array}{l}\text { Time of onset of } \\
\text { motor block }\end{array}$ & $6.8 \pm 1.9$ & $6.5 \pm 1.3$ & 0.572 \\
\hline $\begin{array}{l}\text { Time to reach } \\
\text { highest sensory } \\
\text { level }\end{array}$ & $11 \pm 2.5$ & $11.9 \pm 1.7$ & 0.098 \\
\hline $\begin{array}{l}\text { Time for two } \\
\text { segment } \\
\text { regression }\end{array}$ & $100 \pm 7.5$ & $269.4 \pm 28.9$ & $<0.001$ \\
\hline $\begin{array}{l}\text { Duration of motor } \\
\text { block }\end{array}$ & $159.4 \pm 12.6$ & $357.8 \pm 26.9$ & $<0.001$ \\
\hline $\begin{array}{l}\text { Duration of } \\
\text { analgesia }\end{array}$ & $193.5 \pm 15.6$ & $440.7 \pm 31.9$ & $<0.001$ \\
\hline
\end{tabular}

Intraoperatively no significant difference was observed in vital parameters between the two groups except a fall in blood pressure noted at some time intervals in group $\mathrm{C}$ compared to group $\mathrm{F}$ which was statistically significant. (Figure 1)

Figure 1: Comparison of MAP between two groups

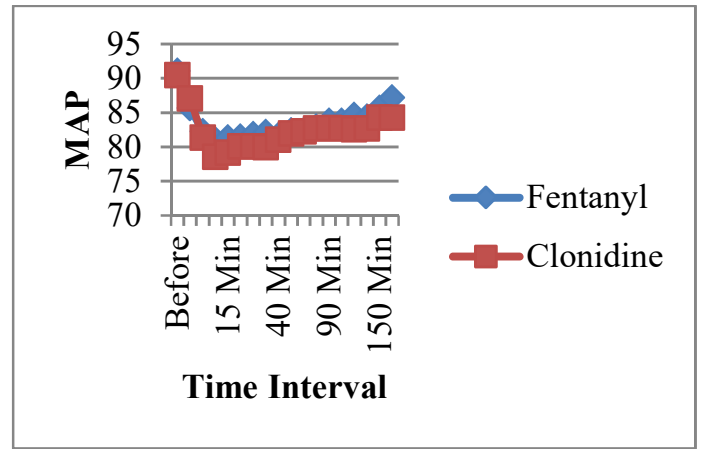

In the fentanyl group, sedation score was 1 in $13.7 \%, 2$ in $70 \%$ and 3 in $16.7 \%$. In clonidine group, $33.3 \%$ had sedation score of 3 and $66.7 \%$ had sedation score of 4 (Table 3 ).

Table 3: Comparison of sedation score between two groups (Chi square test)

\begin{tabular}{|c|c|c|}
\hline Sedation score & $\begin{array}{c}\text { Group F } \\
\mathrm{n}=30\end{array}$ & $\begin{array}{c}\text { Group C } \\
\mathrm{n}=30\end{array}$ \\
\hline 1 & $4(13.7 \%)$ & 0 \\
\hline 2 & $21(70 \%)$ & 0 \\
\hline 3 & $5(16.7 \%)$ & $10(33.3 \%)$ \\
\hline 4 & 0 & $20(66.7 \%)$ \\
\hline
\end{tabular}


4 patients $(13.3 \%)$ in group $F$ were restless and not comfortable in prone position and these patients received propofol infusion. All the patients in group $\mathrm{C}$ were comfortable in prone position ( $\mathrm{p}$ value $=0.038)$ (Table 4).

Table 4: Comparison of patient's comfort in prone position (Chi square test)

\begin{tabular}{|l|c|c|c|}
\hline $\begin{array}{l}\text { Patient's comfort } \\
\text { in prone position }\end{array}$ & Group F & Group C & $\begin{array}{c}\mathrm{p} \\
\text { value }\end{array}$ \\
\hline Restless & $4(13.3 \%)$ & 0 & 0.038 \\
\hline Comfortable & $26(86.7 \%)$ & $30(100 \%)$ & 0.038 \\
\hline Propofol used & $4(13.3 \%)$ & 0 & 0.038 \\
\hline
\end{tabular}

In group $\mathrm{F}$ two patients $(6.7 \%)$ had postoperative vomiting. No other complications were noted in both the groups.

\section{Discussion}

Among the spine surgeries lumbar surgery is more suitable for spinal anaesthesia as the block will be performed in the safest lumbar interspace. ${ }^{2}$ Despite many authors enlightening on the advantages of regional anaesthesia and recommending spinal anaesthesia as a safer and better alternative to general anaesthesia, many anaesthesiologists favour general anaesthesia for lumbar surgeries because airway is well secured in prone position, and longer duration of surgery can be performed easily by extending the general anaesthesia. ${ }^{3,4}$ Lessing et $\mathrm{ll}^{4}$ stated that subarachnoid block is safe and effective even in geriatric patients.

Disadvantages of general anaesthesia over subarachnoid block are airway manipulation, usage of multiple drugs, difficulty in maintaining haemodynamics, inadequate post-operative analgesia, nausea and vomiting. ${ }^{6,7}$ Inducing hypotension in spine surgery under general anaesthesia requires additional usage of drugs which can be easily achieved by subarachnoid block. ${ }^{7}$ Adequate duration of analgesia, providing hypotensive anaesthesia to reduce the intraoperative bleeding in order to give a clear operative field and a calm and comfortable patient in prone position are the main issues to be taken care of by the anaesthesiologist during spinal anaesthesia for spine surgeries. Khattab et $\mathrm{al}^{5}$ observed that seven patients required second dose of subarachnoid block and one patient was converted to general anaesthesia due to prolonged surgery and inadequate analgesia. These issues can be answered by adding an effective adjuvant to the local anaesthetic during spinal anaesthesia for spine surgery.

Intrathecal fentanyl and clonidine are commonly used adjuvants to local anaesthetics in present clinical practice. Intrathecal fentanyl produces analgesia by acting on the G-Protein linked opioid receptors present in the dorsal horn of the spinal cord, thereby opening of potassium channels (mu and delta) and closure of calcium channels (kappa) leading to reduction in release of excitatory transmitters like substance $\mathrm{p}$ and glutamate from presynaptic c fibres. This will reduce the transmission of nociception. Fentanyl due to its structural similarity to local anaesthetics facilitates its analgesic effect. ${ }^{8}$ Clonidine an alpha 2 agonist has a multifactorial mechanism of action on intrathecal local anaesthetics. Analgesic effects are mediated via the alpha 2 receptors located post synaptically on the substantia gelatinosa of the spinal cord. It also causes local vasoconstriction thereby reducing the removal of local anaesthetics surrounding the neural structures resulting in prolongation of block. ${ }^{9}$

In our study both the groups were comparable with respect to age, gender, ASA status, anthropometric measurements and duration of surgery. After giving the block we did not find significant difference regarding mean time of onset of sensory block, motor block and time to reach highest level of sensory block between the two groups. Duration of motor block was significantly prolonged in clonidine group. Clonidine enhances the intensity and duration of motor block by inducing cellular modification in the ventral horn of the spinal cord. ${ }^{9}$ Dobrydnjov et a ${ }^{10}$ however stated that this effect is dose dependant. Kaabachi et $\mathrm{al}^{11}$ stated that $1 \mu \mathrm{g} / \mathrm{kg}$ of clonidine is safe and effective when added to plain bupivacaine.

Both intrathecal fentanyl and clonidine prolonged the duration of action of bupivacaine in our study. Comparison between the two groups showed that at equal volumes the duration of analgesia in clonidine group was almost doubled to that of fentanyl. This is comparable to Sidharth et $\mathrm{al}^{12}$ who found a significant difference in duration of analgesia in their study comparing clonidine 50 
micrograms and fentanyl 25 micrograms as adjuvants. Duration of analgesia depends on the dosage of intrathecal adjuvants used..$^{13}$ Mahendru et $\mathrm{al}^{14}$ observed a duration of analgesia of 243 minutes with 30 micrograms of clonidine whereas we observed a duration of 440 minutes with 50 micrograms of clonidine.

Many of the adjuvants in practice produce sedation with varied intensity and duration. Better the sedation better will be the patient's comfort during surgery. Majority of our patients in clonidine group had a sedation score of 4 and majority of patients who received fentanyl had a sedation score of 2 . Sidharth et $\mathrm{al}^{12}$ also noted a higher sedation with 50 micrograms of intrathecal clonidine than 25 micrograms of fentanyl for orthopaedic surgeries. Clonidine induces dose dependant sedation regardless of route administered. Intrathecal clonidine produces sedation by a $G$ protein mediated inhibitory action on locus coeruleus, the brainstem nucleus which regulates the sleep and wakefulness. ${ }^{9}$ Higher sedation score produced by intrathecal adjuvants are useful for patients undergoing lengthy surgeries in complex positions so that supplementation of intravenous sedation is avoided. ${ }^{14}$

In our study patients in both the groups well accepted the prone position during surgery. All the patients in clonidine group were comfortable and only 4 patients in fentanyl group were uncomfortable requiring propofol infusion and this was statistically significant. In other studies, many of their patients who were supplemented with propofol infusion received 25 micrograms of intrathecal fentanyl. ${ }^{15,16}$ In contrast we observed better patient comfort in fentanyl group which attributes to higher dose of fentanyl used.

Intraoperatively haemodynamics were well maintained in both groups. We observed acceptable hypotension in clonidine group compared to fentanyl group which was helpful in reducing the intraoperative blood loss. Clonidine induces hypotension by potentiating the sympathetic blockade of local anaesthetics, however the degree of hypotension is related to the level of intrathecal clonidine administered in subarachnoid block. ${ }^{13,15}$ Postoperative period was uneventful except vomiting noted in two patients belonging to fentanyl group. Though post spinal headache is a known complication of subarachnoid block, none of our patients developed post dural puncture headache which is in concurrence with Pierce et al ${ }^{17}$ who did not notice any case of post dural puncture headache in patients receiving subarachnoid block for spine surgery. This may be probably due to smaller gauge spinal needle used and bleeding at the operative site will act as a blood patch to seal the dural puncture. ${ }^{2}$

In this study both the intrathecal adjuvants were safe and effective in prone position in respect to achieving desired level of block, maintaining haemodynamics, required duration of analgesia with an advantage of clonidine over fentanyl in view of adequate sedation and patient's comfort without any untoward effects. However, there are some limitations in our study. Sample size was small, and dose selected was arbitrary. Large sample size-based studies and serum level estimations of the adjuvants to establish dose requirements and safety in prone position are required.

\section{Conclusion}

We conclude that intrathecal fentanyl and clonidine are safe and effective in prone position when added to hyperbaric bupivacaine whereas clonidine is a better choice than fentanyl in providing intraoperative patient comfort and postoperative analgesia in patients undergoing single level spine surgery under spinal anaesthesia.

\section{References}

1. Crabb I. Anaesthesia for spinal surgery. Anaesthesia \& Intensive Care Medicine. 2006 Mar 1;7(3):83-6. https://doi.org/10.1383/anes.2006.7.3.83

2. Mergeay M, Verster A, Van Aken D, Vercauteren M. Editorial. Regional versus general anesthesia for spine surgery. A comprehensive review. Acta AnestesiolBel.2015;66:1-9.

PMid:26103736

3. Jellish WS, Thalji Z, Stevenson K, Shea J. A prospective randomized study comparing short- and intermediate-term perioperative outcome variables after spinal or general anesthesia for lumbar disk and laminectomy surgery. Anesthesia \& Analgesia. 1996Sep1;83(3):559-64.

https://doi.org/10.1213/00000539-19960900000021

PMid:8780281

4. Lessing NL, Edwards CC, Brown $\mathrm{CH}$ et al. Spinal anesthesia in elderly patients undergoing lumbar spine surgery. Orthopedics. 2017 Mar 24;40(2):e317-22. 
https://doi.org/10.3928/01477447-20161219-01

PMid:28027388

5. Khattab M, El-Hawary Y, El-Ghamry S, Montasser A. Spine Surgery under Spinal Anaesthesia. Global Spine Journal. 2016 Apr;6(1_suppl): s-0036.

6. McLain RF, Kalfas I, Bell GR, Tetzlaff JE, Yoon HJ, Rana M. Comparison of spinal and general anesthesia in lumbar laminectomy surgery: a casecontrolled analysis of 400 patients. Journal of Neurosurgery: Spine. 2005 Jan;2(1):17-22. https://doi.org/10.3171/spi.2005.2.1.0017

PMid:15658121

7. Raw DA, Beattie JK, Hunter JM. Anaesthesia for spinal surgery in adults. British Journal of Anaesthesia. 2003 Dec 1;91(6):886-904. https://doi.org/10.1093/bja/aeg253

PMid:14633762

8. Hindle A. Intrathecal opioids in the management of acute postoperative pain. Continuing Education in Anaesthesia, Critical Care \& Pain. 2008 May 2;8(3):81-5.

https://doi.org/10.1093/bjaceaccp/mkn016

9. Eisenach JC, De Kock M, Klimscha W. $\alpha 2-$ Adrenergic Agonists for Regional Anesthesia. A Clinical Review of Clonidine (1984-1995). Anesthesiology: The Journal of the American Society of Anesthesiologists. 1996 Sep 1;85(3):65574.

10. Dobrydnjov I, Axelsson K, Thörn SE et al. Clonidine combined with small-dose bupivacaine during spinal anesthesia for inguinal herniorrhaphy: a randomized double-blinded study. Anesthesia \& Analgesia. $2003 \quad$ May 1;96(5):1496-503. https://doi.org/10.1213/01.ANE.0000061110.6284

1.E9

PMid:12707157

11. Kaabachi O, Zarghouni A, Ouezini R, Abdelaziz $\mathrm{AB}$, Chattaoui O, Kokki H. Clonidine $1 \mu \mathrm{g} / \mathrm{kg}$ is a safe and effective adjuvant to plain bupivacaine in spinal anesthesia in adolescents. Anesthesia \& Analgesia. 2007 Aug 1;105(2):516-9. https://doi.org/10.1213/01.ane.0000268709.67572. $\underline{09}$

PMid:17646515

12. Routray SS, Raut K, Pradhan A, Dash A, Soren M. Comparison of intrathecal clonidine and fentanyl as adjuvant to hyperbaric bupivacaine in subarachnoid block for lower limb orthopedic surgery. Anesthesia, essays and researches. 2017 Jul;11(3):589.

13. Hayashi Y, Maze M. Alpha 2 adrenoceptor agonists and anaesthesia. British Journal of Anaesthesia. 1993Jul;31;71(1):108-18.

https://doi.org/10.1093/bja/71.1.108

PMid:8102063
14. Mahendru V, Tewari A, Katyal S, Grewal A, Singh MR, Katyal R. A comparison of intrathecal dexmedetomidine, clonidine, and fentanyl as adjuvants to hyperbaric bupivacaine for lower limb surgery: A double blind controlled study. Journal of anaesthesiology, clinical pharmacology. 2013 Oct;29(4):496.

https://doi.org/10.4103/0970-9185.119151

PMid:24249987 PMCid:PMC3819844

15. Attari MA, Mirhosseini SA, Honarmand A, Safavi MR. Spinal anesthesia versus general anesthesia for elective lumbar spine surgery: A randomized clinical trial. Journal of research in medical sciences: the official journal of Isfahan University of Medical Sciences. 2011 Apr;16(4):524.

16. Bajwa BS, Singh AP, Rekhi AK. Comparison of intrathecal clonidine and fentanyl in hyperbaric bupivacaine for spinal anesthesia and postoperative analgesia in patients undergoing lower abdominal surgeries. Saudi journal of anaesthesia. 2017 Jan;11(1):37.

https://doi.org/10.4103/1658-354X.197337

PMid:28217051 PMCid:PMC5292850

17. Pierce JT, Kositratna G, Attiah MA, Kallan MJ, Koenigsberg R, Syre P, Wyler D, Marcotte PJ, Kofke WA, Welch WC. Efficiency of spinal anesthesia versus general anesthesia for lumbar spinal surgery: a retrospective analysis of 544 patients. Local and regional anesthesia. 2017;10:91. https://doi.org/10.2147/LRA.S141233

PMid:29066932 PMCid:PMC5644537 